\title{
Percepções de profissionais de enfermagem sobre humanização do parto em ambiente hospitalar
}

\author{
Perceptions of nursing professionals about humanization of childbirth in a hospital \\ environment
}

Mariana Cavalcante Ferreira ${ }^{1}$, Lorenna Viccentine Coutinho Monteschio ${ }^{1}$, Elen Ferraz Teston ${ }^{2}$, Lidiaine Oliveira ${ }^{1}$, Deise Serafim ${ }^{1}$, Sonia Silva Marcon ${ }^{1}$

\begin{abstract}
Objetivo: compreender as percepções de profissionais de enfermagem quanto à humanização do parto. Métodos: pesquisa qualitativa, desenvolvida com 20 profissionais de enfermagem de hospital universitário. Dados coletados por meio da observação não participante e entrevista semiestruturada, áudio gravado, guiada pela questão norteadora: como você percebe a humanização do parto no contexto do seu trabalho? As entrevistas foram transcritas na íntegra e submetidas à análise de conteúdo, modalidade temática. Resultados: emergiram as categorias: Significados atribuídos à humanização do parto e Aspectos dificultadores da humanização do parto. Conclusão: os profissionais ressaltaram as ações realizadas que refletem na humanização do parto, mas destacaram as dificuldades relacionadas às questões estruturais e de recursos que refletem negativamente na qualidade da assistência prestada, além de transferirem a responsabilidade de melhoria do serviço, que é de todos, somente aos gestores.
\end{abstract}

Descritores: Parto Humanizado; Enfermagem Obstétrica; Cuidados de Enfermagem; Humanização da Assistência.

Objective: to understand the perceptions of nursing professionals regarding the humanization of childbirth. Methods: a qualitative research, developed with 20 nursing professionals from a university hospital. Data collected through a non-participant observation and semi-structured interviews, recorded audio, guided by the following question: how do you perceive the humanization of childbirth in your work context? The interviews were fully transcribed and subjected to content analysis, thematic mode. Results: the following categories emerged: Characteristics attributed to the humanization of childbirth and Difficulties hindering humanization of childbirth. Conclusion: the professionals highlighted both the actions taken that reflect on the humanization of childbirth, and also the difficulties related to the structural and resource issues, that negatively reflect on the care quality provided, besides transferring the responsibility for improving the service, which belongs to everyone, not only to managers.

Descriptors: Humanizing Delivery; Obstetric Nursing; Nursing Care; Humanization of Assistance.

\footnotetext{
${ }^{1}$ Universidade Estadual de Maringá. Maringá, PR, Brasil.

${ }^{2}$ Universidade Federal de Mato Grosso do Sul. Campo Grande, MS, Brasil. 


\section{Introdução}

A humanização do parto é a alternativa mais apropriada aos modelos biomédico e tecnológico vigentes para melhorar a assistência à parturiente e ao recém-nascido, uma vez que constitui fator que favorece o trabalho de parto e o vínculo mãe e bebê $\hat{e}^{(1)}$. Neste sentido, abordagem centrada nas mulheres, com respeito a direitos, valores, crenças, autonomia, escolhas e controle sobre seus corpos e processo de nascimento, constituem conceitos-chave do parto humanizado(2).

As práticas humanizadas consistem em oferecer à gestante e respectivo familiar apoio e informações necessárias para o trabalho de parto e parto qualificado $^{(3)}$. Incluem cuidados como: orientar a gestante quanto à alimentação, deambulação, contrações dolorosas e escolha da posição pela paciente durante o trabalho de parto e parto, direito ao acompanhante e local do parto ${ }^{(4)}$.

Concernente a isso, estudo realizado com 51 mães em alojamento conjunto de hospital municipal de Fortaleza, Brasil, apresentou algumas práticas efetivas de cuidado durante o trabalho de parto, destacando-se: o apoio empático por parte dos profissionais, o uso de métodos não farmacológicos para alívio da dor e a liberdade de posição durante o trabalho de parto $^{(5)}$.

Contudo, o cenário geral da assistência obstétrica, ainda, é permeado por obstáculos que dificultam a implementação de ações humanizadas, as quais contemplam o acesso, o acolhimento, a qualidade e a resolutividade ${ }^{(4)}$. Estudo que entrevistou mulheres no puerpério imediato e levantou informações do prontuário hospitalar, constatou a baixa adesão a boas práticas durante o trabalho de parto e parto, representada, por exemplo, por elevada frequência de medicalização durante estes períodos ${ }^{(6)}$.

Por sua vez, estudo realizado na Tanzânia evidenciou que normas e práticas institucionais que proibiam o envolvimento da família durante o processo do nascimento, incluindo crenças que limitavam a escolha da posição de nascimento, influenciavam negativamente na humanização da assistência. Ademais, fatores como espaço físico insuficiente, escassez de recursos humanos qualificado, atitudes e crenças com foco no profissional médico influenciam na assistência de qualidade ao parto. Portanto, torna-se necessário superar essas barreiras e oportunizar a qualificação profissional, para que possam realizar ações que contribuam para o cuidado integral e centrado no paciente $^{(7)}$. Para tanto, questionou-se: como os profissionais de enfermagem percebem a humanização do parto na prática diária?

Diante do exposto e do cenário atual, em que ainda existem muitos obstáculos para implementação de ações humanizadas durante o pré-natal, parto e puerpério, definiu-se como objetivo do estudo: compreender as percepções de profissionais de enfermagem quanto à humanização do parto.

\section{Métodos}

Estudo qualitativo, realizado com profissionais de enfermagem das unidades de Ginecologia e Obstetrícia e Centro Cirúrgico de hospital universitário do noroeste do Paraná, Brasil, referência para o acompanhamento de gestantes de risco habitual e alto risco. A unidade de Ginecologia e Obstetrícia possuía, na ocasião do estudo, cinco enfermarias, com três leitos cada (nove para alojamento conjunto, três para internação cirúrgica da ginecologia e três para tratamento clínico de gestantes com intercorrências), e um quarto com dois leitos, designado de pré-parto. 0 centro cirúrgico tinha três salas de cirurgia e uma sala para parto vaginal. As cesarianas ocorriam nas salas cirúrgicas. As parturientes permaneciam no pré-parto durante o trabalho de parto e são encaminhadas ao Centro Cirúrgico, no período expulsivo.

Atuavam na unidade de Ginecologia e Obstetrícia cinco enfermeiras (apenas uma especialista em obstetrícia) e 15 técnicos de enfermagem e, no Centro cirúrgico, oito enfermeiros e 18 técnicos. 0 critério de inclusão adotado foi trabalhar no respectivo setor há 
pelo menos seis meses. Foram excluídos os profissionais em férias, licença ou afastamento, o que resultou na participação de 20 profissionais.

Os dados foram coletados de agosto a outubro de 2017, por meio da observação livre e entrevista semiestruturada. A observação do tipo não participante ocorreu durante o último estágio do curso de graduação em Enfermagem da primeira autora. As entrevistas aconteceram de acordo com a disponibilidade dos participantes, em sala reservada, na própria instituição, e durante o turno de trabalho, com interferência mínima nas atividades do setor. Tiveram duração média de 25 minutos, foram gravadas em mídia digital e, posteriormente, transcritas na íntegra. Durante as mesmas, utilizou-se de formulário para caracterização sociodemográfica e da questão norteadora: como você percebe a humanização do parto no contexto do local de trabalho que atua? Questões auxiliares foram utilizadas quando foram necessários maior explanação e aprofundamento dos dados.

Os dados qualitativos, incluindo os provenientes do diário de campo, foram submetidos à análise de conteúdo, modalidade temática, seguindo as três etapas propostas ${ }^{(8)}$. Na pré-análise, realizaram-se leituras flutuantes e intensivas do conjunto dos dados, para sistematização das ideias iniciais e levantamento dos pontos relevantes ao objetivo do estudo. Na segunda etapa, de exploração do material, procedeu-se à codificação dos dados brutos que foram transformados sistematicamente e agregados em unidades. Por fim, na etapa de tratamento dos dados, realizou-se a categorização, com classificação dos elementos, segundo semelhanças, e por diferenciação, com posterior reagrupamento, em função de características comuns, com identificação de duas categorias.

O estudo foi desenvolvido em consonância com as diretrizes da Resolução 466/2012 do Conselho Nacional de Saúde e o projeto aprovado pelo Comitê de Ética em Pesquisa com Seres Humanos da Universidade Estadual de Maringá (Parecer no 2.230.676/2017). Os participantes assinaram o Termo de Consentimento Livre e Esclarecido e estão identificados pelas letras
E (enfermeiros) e T (técnicos de enfermagem), seguidas de número indicativo da ordem de realização das entrevistas.

\section{Resultados}

Foram entrevistados 20 profissionais de enfermagem, destes, dez atuavam na Ginecologia e Obstetrícia (duas enfermeiras e oito técnicas) e dez no Centro Cirúrgico (quatro enfermeiras e seis técnicas). Dezenove eram do sexo feminino, a idade média dos participantes foi de 40 anos e o tempo de trabalho nas respectivas unidades variou de um a 26 anos.

Ao considerar as recomendações da Organização Mundial da Saúde ${ }^{(9)}$, no estágio curricular, observaram-se elementos que dificultavam a humanização da assistência durante o trabalho de parto, dentre os quais: não valorização da luz natural, utilização do quarto de pré-parto como depósito de equipamentos e reduzido incentivo à deambulação e experimentação de diferentes posições durante o trabalho de parto, inviabilizando a escolha de posição que proporcionasse maior conforto e que favorecesse a evolução do trabalho de parto. Também, identificaram-se ações que beneficiavam a parturiente e favoreciam a evolução do trabalho de parto, como: orientações sobre atividades para estimulá-lo, como banho morno e respeito ao direito de ter um acompanhante de escolha. A partir da análise das entrevistas, emergiram duas categorias temáticas, descritas a seguir.

\section{Significados atribuídos à humanização do parto}

Ao manifestarem concepções, os participantes, frequentemente, apontaram alguns aspectos estruturais e organizacionais relacionados às rotinas do serviço, como promotores da humanização do parto: Humanização é você tentar deixar tudo mais tranquilo, mais gostoso o ambiente (E1). Eu acho que quanto menos interferência, menos barulho, menos estresse... Um ambiente propício, com menos luz, menos conversação, uma música bem calma (T1). O obstetra ou o residente ali, mais um profissional que possa ajudar o outro da pediatria, quem vai recepcionar, esó, pouca gente (T13). 
Também, citaram algumas ações com o mesmo propósito, como a não medicalização do parto e a restrição de procedimentos, como a episiotomia: Como humanização, eupercebo que é você conduzir um parto de uma forma que ele vá se desenvolver o mais natural possível, sem medicação, sem muita interferência humana, os partos que acontecem sem episiotomia, sem agressão(T5).

Além disso, apontaram a importância de proporcionar alívio da dor, por meio de medidas não farmacológicas, e permitir o contato pele a pele entre a mãe e o bebê o mais precocemente possível: Fazer massagem que conforta bastante, relaxa. Agente orientar o banho morno, o próprio exercício nesta bolona e nos materiais que a gente tem (T5). Colocar a criança em contato com a mãe... é importantíssimo a criança já sair do centro cirúrgico sugando na mãe, tendo aquele contato pele a pele..., o centro cirúrgico tem pecado muito nesse quesito (T7).

Evidenciou-se que, para os profissionais pesquisados, o propulsor da humanização do parto é a relação profissional/parturiente, permeada pelo acolhimento individualizado e empático, e o diálogo direcionado ao atendimento das necessidades da mulher em trabalho de parto: Para mim, humanizar é fazer a parturiente sentir que naquele momento estamos vendo o caso único dela, fazendo de tudo para ela se sentir acolhida (E5). Interna uma gestante, aí você a recebe e começa a conversar com ela, saber de seu contexto, número de filhos... Tudo isso vai te aproximando dela, ela vai adquirindo confiança e, a partir disso, você começa a interagir muito mais facilmente, ela vai fazer as técnicas que a gente tem de humanização de parto, de forma muito mais natural, muito mais cooperativa, mais espontânea, sem você impor (T3). Humanizar é você tratar a pessoa como você gostaria de ser tratado; ése colocar no lugar dela; chamarpelo nome $(\mathrm{E} 4)$.

Outro aspecto da humanização destacado foi a valorização do direito de escolha em relação, por exemplo, à posição do parto: Na verdade, no parto humanizado, o que é preconizado é que ela tenha a escolha da posição. Que ela opte pela posição que achar mais favorável. Se quiser ficar de cócoras, ficar de quatro, ficar sentada na banquetinha ... a gente poderia orientar para que ela, no finalzinho do trabalho de parto, pudesse testar essas posições e ver em qual se sente melhor, não impor...(T3). Tem que respeitar a gestante, ela quem deve decidir se gosta daquela forma ou não. Se ela quer de cócoras, vamos lá, gente. Ela que tem que decidir, porque falam muito nos direitos da mulher, masna hora do parto, fica travando umas coisas. Acho que se ela quer, pode ser feito (T4).

0 que envolve, inclusive, o respeito as escolhas relacionadas às posições e medidas não farmacológicas de alívio da dor durante a evolução do trabalho de parto: Não é porque você sabe que é o melhor, que vai ser o mais rápido para ela. Se você torna isso uma obrigação, acabou a humanização. Então, ela tem o direito de escolha (E6). Oh, vai ser melhor para você, vai descer mais rápido, vai aliviar a dor, vai nascer mais rápido. Mas, eu não quero! Então, está ok (E6). Eu quero que você caminhe, que você vá para bola. Eu não quero! Vai demorar mais, mas é uma decisão dela. Isso éhumanizar(E6).

$\mathrm{Ou}$, ainda, a valorização do direito de escolha do acompanhante: Se ela escolheu, se para ela está confortável, a gente tem que respeitar. Porque não é para nós, é para ela. Nós, enquanto profissionais, não temos que gostar ou não daquele acompanhante porque é dela (T4). Para mim, a humanização do parto seria a família próxima (T8).

\section{Aspectos dificultadores da humanização do parto}

A rotina institucional e o dimensionamento de pessoal foram referidos como elementos dificultadores da humanização no parto, destacando-se a pouca disponibilidade de tempo e o número limitado de funcionários: Raramente você consegue, por falta de tempo, de funcionário. Você tem coisas mais urgentes para resolver. Então, tem queoptar: ou você atua lá fora (alojamento conjunto egerenciamento do setor) ou aqui dentro (quarto de pré-parto). Aí, quando dá, sobrou um tempinho, você vem. Não tem como você ficar horas aqui, junto e direto. Precisou, alguém chamou, a gente vem, se não, não vem. A não ser que você largue tudo e fique aqui. Mas, e o restante lá?(E1).

A ausência de profissional escalado para acompanhar o trabalho de parto foi mencionada como fator que influencia negativamente a assistência humanizada, por limitar a atuação dos profissionais ao fornecimento de algumas orientações: A gente cuida de vários outros pacientes. Então, muitas vezes, ela fica aqui como familiar, e quando não, ela fica só. Então, não tem aquela doula que orienta e tal. A gente faz as primeiras orientações, mas não fica o tempo todo alguém aqui assistindo. Então, eu acho que o nosso parto não é humanizado. Na minha opinião, nãoé(T9).

Durante o estágio curricular, observou-se que as mulheres em trabalho de parto nem sempre recebiam a assistência recomendada. Isto porque, apesar de acreditarem na importância da humanização do parto, priorizavam outras atividades, inclusive nos dias e momentos em que a unidade estava com ocupação reduzida de pacientes, como identificado em registro no diário de campo: Vejo que a paciente fica muito 
tempo sozinha no pré-parto, tanto no período da manhã, quanto à noite. Estava calmo, os profissionais poderiam ter ido orientar, conversar, principalmente quando ela estava chorando de dor. Acho que falta essa presença. Pelo menos durante as horas em que estive ali, ninguém foi saber como a paciente estava e a equipe estava, de certa forma, disponível. Poderiam terido láe dado atenção para a gestante e o familiar (Nota do Diário de Campo).

As funcionárias da Ginecologia e Obstetrícia ressaltaram que para reverter essa situação há necessidade de profissional exclusivo para garantir assistência humanizada às mulheres em trabalho de parto: ...Teria que ter um técnico específico por período. Internou gestante em trabalho de parto, ele vai ficar só ali na sala de pré-parto, dando essa assistência o tempo todo (T3).

No que se refere à alimentação, observou-se divergência de opiniões. Enquanto na Ginecologia e Obstetrícia a alimentação da paciente em trabalho de parto era liberada, os profissionais do Centro Cirúrgico foram contrários a essa rotina, por acreditarem que isto poderia causar complicações à parturiente: Eu falo enquanto centro cirúrgico, entrou em trabalho de parto, tem que ficar em jejum. Se der um problema, tiver que fazer uma cesárea, corre risco de vomitar e ter uma complicação. Mesmo que for normal, porque pode complicar. Acho que pelo menos seis horas a mãe tem que aguentar. Sem água e sem comida. Acho que a paciente que está em trabalho de parto não tem fome, não épossivel. Fica com aquelas dores horríveis, porque é horrível (T11).

Em relação às posições durante o trabalho de parto e parto, os profissionais reconheceram que, na instituição estudada, as condutas tomadas eram anti-humanização: Ela faz aquilo que está orientada a fazer, ninguém fala: olha, você fica do jeito que você quiser enós vamos recepcionar o seu neném na hora que tiver nascendo. Eu nunca ouvi alguém dizendo isso. Ela chega e vocêjá coloca na posição ginecológica, ela nem sonha que existe outro tipo de posição porque quem tem que orientar é o profissional, se ele não está disposto a orientar e fazer diferente, não vai ser feito diferente(T1). Não incentivam uma outra posição não. É sempre essa (T14). Como é que nós vamos conseguir humanizar aqui. É complicado, queméque vai peitar esses médicos (T6).

Além disso, alguns profissionais relataram acreditar que essa posição seria a ideal: É a posição mais apropriada, a mais confortável que tem (T14). Durante o estágio, observou-se que a posição ginecológica adotada em todas as ocasiões não era a mais cômoda, conforme impressão registrada: A paciente ficava escorregando o tempo todo. À medida que ela fazia força, ela começava a escorregar. Dava a impressão que a qualquer momento, ela iria cair. Aí, a enfermeira ia por trás da mesa e puxava o colchão para cima para a parturiente não cair da mesa. Então, assim, aparentemente, o local e a posição eram bem ruins. A mesa desconfortável e a gestante com dor a cada contração. Uma posição muito ruim, uma mesa muito ruim, na qual ela ficava escorregando o tempo todo (Diário de Campo).

Os participantes acreditavam que o fato de ser hospital de ensino inviabilizava a assistência humanizada em totalidade, havendo, inclusive, conformismo diante da situação: Aqui, ela não tem privacidade nenhuma, não tem como ter privacidade em um hospital de ensino. Porque entra o obstetra, o residente, os internos, os alunos, o esposo, às vezes, os técnicos de enfermagem, não tem privacidade, não tem como terprivacidade. Às vezes, vocêchega em uma sala de parto e tem umas 10 pessoas (T14).

Os profissionais dos dois setores justificaram a ausência de ações voltadas para humanização do parto pela inexistência de centro obstétrico: Não, aqui, no setor da Ginecologia e Obstetrícia... deveria ter um centro obstétrico alguma coisa lá, ligado ao centro cirúrgico, precisou, ocorreu alguma emergência, precisou de alguma coisa para oneném, tem tudo lá, tem médico presente, anestesiologista, se precisar, então, eu acho que assistência lá seria melhor (E1). O ideal é que tivesse um centro obstétrico em que não fosse só vir aqui para ganhar o neném. Que ela ficasse ali,já num ambiente que fosse preparado. Eu já tive em hospitais que têm centro obstétrico, fazendo estágio, fazendo acompanhamento. É totalmente diferente. A mulher já é admitida no centro obstétrico e fica ali todo o processo. Eles conseguem falar assim: Ah, eu tenho um atendimento mais humanizado (E3).

E, ainda, alguns profissionais ressaltaram que a humanização do parto somente ocorrerá, verdadeiramente, se as ações forem iniciadas desde o pré-natal: Tem que iniciar no pré-natal. As coisas têm que começar de uma base, a humanização inclusive. Pegar lá no princípio, porque do meio para frente (T5).

Apontaram como deficiência dessa esfera de assistência o despreparo do familiar acompanhante que, muitas vezes, desconhece o próprio papel: Acho que para ser bom, tem que começar lá no posto de saúde, no pré-natal. Porque nem todos chegam aqui preparados. É difícil vir um acompanhante orientado. Eles dão trabalho. A maioria dá. Dez por cento ajuda, mas a maioria atrapalha (T9). Ele tem que saber que o foco dele não é tirar foto, é acompanhar, dar apoio. Então, assim, teria que começarno pré-natal(E4).

A carência de adesão dos profissionais e o posicionamento por parte dos gestores também foram percebidos como dificuldades: Eu acho que falta vontade política. Sabe?! Falta decisão do hospital de falar: Vamos fazer assim! Vai ser assim agora (E5)! Porque a gente tem profissionaisótimos que são voltados para humanização, os que não são, vão 
chegar aqui, acharmil e uma desculpas e vão fazer uma cesárea. Vão fazertudoo queéiatrogenia: romper bolsa, colocarocitocina. Então, assim, enquanto isso não vier da superintendência, do poder do hospital: Vamos fazer quantos workshops quiserem, mas a gente vaificar assim! Não vai acontecer(E6).

\section{Discussão}

O estudo foi realizado em hospital escola, o que pôde influenciar o conhecimento dos profissionais quanto às questões preconizadas pelas políticas vigentes. Ademais, a instituição tinha estrutura física que não era totalmente condizente com a política de humanização, à medida que, por exemplo, não possuía quarto de pré-parto, parto e puerpério. Assim, aponta-se como limitação a interferência destes fatores nas percepções dos profissionais pesquisados sobre a humanização e a possibilidade de terem feito referência ao que é preconizado e não, necessariamente, à prática vivenciada no contexto de trabalho. De qualquer modo, os resultados oferecem subsídios para que os profissionais reflitam sobre a prática cotidiana e implementem ações de cuidado fundamentadas nos princípios da humanização.

Na categoria Significados atribuídos à humanização do parto, observou-se que, para alguns depoentes, humanizar a assistência ao parto envolve proporcionar à mulher ambiente acolhedor, agradável e aconchegante, caracterizado pela penumbra e ausência de ruídos. Esta percepção corrobora o que é estabelecido pela Política Nacional de Humanização e pela Rede Cegonha, que ressalta, por exemplo, a importância do ambiente acolhedor e confortável, com controle da iluminação e de ruídos ${ }^{(1)}$.

Nesse sentido, reitera-se a importância de os profissionais terem conhecimento acerca das ações que favorecem a adequação do ambiente e o atendimento à parturiente. A Organização Mundial da Saúde apresenta recomendações e propõe condutas para reduzir as intervenções médicas desnecessárias, como essenciais a humanização ${ }^{(9)}$. Dentre estas, destacam-se os cuidados necessários durante o trabalho de parto, parto e pós-parto imediato para parturiente e recém-nascido; a escolha de acompanhante durante o trabalho de parto e nascimento; o respeito e a boa comunicação entre as mulheres e a equipe de saúde; a preservação da privacidade; a liberdade de escolha de posições para o trabalho de parto e parto; e as medidas não farmacológicas para alívio da dor ${ }^{(9)}$.

Outro quesito destacado pela Organização Mundial da Saúde é o respeito ao ritmo de dilatação cervical durante o trabalho de parto ativo, que não pode ser padronizado, pois é impreciso na ocorrência de distócias durante o parto e que um ritmo de dilatação mais lento não deve ser motivo para acelerar o parto ou nascimento ${ }^{(9)}$. Portanto, a conduta de acelerar o processo do trabalho de parto induz o profissional a intervenções desnecessárias, tornando a experiência de parir desagradável, além de prejudicar o evento do parto natural ${ }^{(8)}$.

Também citaram algumas ações com o mesmo propósito, como a não medicalização do parto e a restrição de procedimentos, como a episiotomia. Estudo com enfermeiras de centro obstétrico, na Região Sul do Brasil, constatou que elas julgavam fundamental que as práticas obstétricas intervencionistas fossem evitadas e recomendavam a adoção de técnicas não farmacológicas para o alívio da dor, a fim de proporcionar atenção humanizada ao parto. Para as pesquisadas, a assistência com base em procedimentos invasivos, além de descaracterizar o nascimento natural, faz com que a parturiente deixe de ser protagonista deste processo, transferindo este papel aos profissionais ${ }^{(10)}$. Do mesmo modo, no presente estudo, os participantes destacaram a importância de práticas não farmacológicas para humanização do cuidado e conferiram destaque especial a não medicalização do parto e restrição de alguns procedimentos, como a episiotomia.

Observou-se que, na concepção dos profissionais investigados, incentivar e proporcionar o contato pele a pele entre mãe e bebê e promover o aleitamento materno logo após o nascimento também caracterizam ações que favorecem a humanização do parto e a formação do vínculo entre mãe e filho desde o primei- 
ro minuto de vida. Enfatiza-se que os primeiros minutos após o nascimento constitui "período sensível" para programar fisiologia e comportamento futuros, além de representar maior probabilidade de sucesso da amamentação exclusiva ${ }^{(11)}$, conforme orientado pelas Diretrizes Nacionais de Assistência ao Parto Normal $^{(12)}$ e recomendado em estudos nacionais e internacionais ${ }^{(1-2,7,7)}$.

A relação empática entre profissional e parturiente também foi referida como contribuinte para humanização do parto, corroborando resultados de outros estudos, como o realizado com enfermeiras de hospital de ensino no país, que destacaram o acolhimento, a individualidade de cada paciente, o diálogo e a empatia como recursos que humanizam o parto $^{(10)}$. Estudo de revisão de teses e dissertações sobre a temática ${ }^{(13)}$, também, identificou as relações interpessoais como características da assistência humanizada. Destarte, o acolhimento contribui para o bom relacionamento entre os envolvidos e evita situações estressantes para mulher, além de permitir que o profissional demonstre atenção e disponibilidade para compreender expectativas e esclarecer dúvidas ${ }^{(10)}$.

0 direito da parturiente em ter um acompanhante de escolha e a liberdade em optar pela posição percebida como mais confortável durante o trabalho de parto e parto, também, foram apontados como práticas de humanização. Contudo, essa concepção não foi unanimidade entre os profissionais, pois alguns destacaram a necessidade de os familiares serem preparados para (re)conhecerem o respectivo papel nesse contexto. Essa concepção é distinta dos resultados obtidos em pesquisa com profissionais de enfermagem do Hospital da Mulher Mãe Luzia, em Macapá, Amapá, Brasil, que entendem que o acompanhante de escolha da parturiente beneficia o processo do parto e nascimento ${ }^{(14)}$.

Desse modo, destaca-se a importância de os profissionais de saúde oportunizarem e estimularem a busca de garantia dos direitos da parturiente em relação ao acompanhante - ação respaldada legalmente e que influencia positivamente na humanização do parto. Pesquisa com enfermeiros de maternidade no Rio de Janeiro, Brasil, evidenciou que estes consideram indispensável à humanização do parto que os profissionais reconheçam, respeitem e contribuam para que a parturiente tenha consciência e autonomia no exercício de seus direitos ${ }^{(15)}$.

Por sua vez, na categoria Aspectos dificultadores da humanização, a sobrecarga profissional foi apontada pelas enfermeiras da Ginecologia e Obstetrícia como uma das principais dificuldades para realizar a assistência humanizada, pois, além de atender às parturientes, a demanda do setor envolve o atendimento a puérperas e filhos, pacientes de internação cirúrgica de ginecologia, deixando evidente que a assistência às mulheres em trabalho de parto não é priorizada.

A sobrecarga de trabalho dos profissionais de enfermagem é uma realidade e isto pode afetar a qualidade da assistência, a relação com a equipe de trabalho e as usuárias. Pesquisa sobre a carga de trabalho psíquica em enfermeiros que atuam em maternidades do país mostra que o enfermeiro tem dificuldade em conciliar as atividades administrativas e assistenciais, o que reduz a atuação na assistência direta, pois as demandas que emergem no ambiente de trabalho para efetivação da assistência, recaem sobre ele, limitando o tempo que poderia ser dedicado à parturiente ${ }^{(16)}$.

Nesse sentido, os profissionais destacaram a necessidade de repensar a distribuição e organização dos recursos humanos e, inclusive, a ampliação do quadro de profissionais que atuam neste setor, de modo que haja profissionais para prestar assistência exclusiva à parturiente, como a doula ou outro profissional da equipe, com atribuição específica e devidamente capacitado para tal. Enfermeiras de maternidade conveniada ao Sistema Único de Saúde em Piracicaba, São Paulo, Brasil, apontaram os benefícios da presença da doula, em especial com relação ao apoio físico e emocional oferecido à parturiente, além do fornecimento de informações durante o trabalho de parto e parto, que contribuem para redução de medidas farmacológicas, de cesarianas, além de proporcionar à mulher 
maior segurança, confiança e satisfação quanto à experiência do parto ${ }^{(17)}$.

Ainda, entre as práticas que dificultam a humanização do parto, destacaram-se as relacionadas às condutas médicas, o que corrobora achados de outro estudo com profissionais de enfermagem ${ }^{(18)}$. Estes resultados mostram que a decisão e o poder que os médicos detêm sobre a assistência durante o parto ainda sobressaem, ou seja, que, em muitos locais, até mesmo no hospital lócus do presente estudo, os profissionais de enfermagem não possuíam autonomia na condução da assistência ao trabalho de parto e parto.

A posição indicada pelos profissionais para o parto e nascimento foi percebida claramente como um dos elementos da rotina institucional que mais impede a concretização da assistência humanizada. Estudo realizado em centro obstétrico de hospital de ensino do município de Pelotas, Rio Grande do Sul, Brasil, também identificou que a única posição para o parto permitida pelos profissionais era a litotômica ${ }^{(19)}$. Deste modo, torna-se necessário o desenvolvimento de ações junto à equipe que promovam sensibilização quanto aos benefícios da valorização, quando possível, das escolhas da parturiente, inclusive com relação à posição para o parto.

Por vezes, a negligência em promover a privacidade da parturiente foi apontada como um dos elementos que ocorre diariamente na instituição e que influencia negativamente a humanização da assistência prestada. Esse comportamento também foi sinalizado em estudo com enfermeiras de maternidade de Piracicaba, São Paulo, Brasil, as quais reconheceram a falta de privacidade às parturientes internadas no serviço ${ }^{(17)}$. Assim, destaca-se a necessidade urgente do planejamento de ações que revertam essa desumanização e garantam a privacidade da parturiente, permitindo que esta atribua significados a esse momento e faça escolhas e, sempre que possível, respeitem princípios e crenças da paciente ${ }^{(20)}$.

Com vistas à efetiva qualificação e humanização do parto, os profissionais destacaram, também, a necessidade do envolvimento da equipe de gestão hospitalar no planejamento e na implementação de práticas voltadas à humanização. Destarte, oportunizar discussões entre os profissionais atuantes diretamente na assistência e na gestão favorece a elaboração de diferentes estratégias que promovam o cuidado hu$\operatorname{manizado}^{(10)}$.

\section{Conclusão}

De acordo com os profissionais de enfermagem pesquisados, a humanização do parto possui significados que englobam aspectos estruturais e organizacionais da instituição; a relação profissional-parturiente e o respeito a autonomia e direitos de escolha da mulher. Reconheceram que atitudes e cuidados simples, como empatia, alimentação e iluminação constituem boas práticas para o parto humanizado e são viáveis no contexto de trabalho, pois não dependem de tecnologia ou grandes investimentos em infraestrutura. Por sua vez, apontaram como dificultadores aspectos diretamente relacionados à rotina institucional e escassez de profissionais qualificados para atenção exclusiva à parturiente durante o trabalho de parto, bem como inexistência de centro obstétrico.

\section{Colaborações}

Ferreira MC colaborou com concepção e projeto, análise e interpretação dos dados, redação do artigo. Monteschio LVC e Oliveira L colaboraram com redação do artigo e aprovação final da versão a ser publicada. Teston EF, Serafim D e Marcon SS contribuíram com redação do artigo, revisão crítica relevante do conteúdo intelectual e aprovação da versão final a ser publicada.

\section{Referências}

1. Polgliane RBS, Leal MC, Amorim MHC, Zandonade E, Santos Neto ET. Adequação do processo de assistência pré-natal segundo critérios do Programa de Humanização do Pré-natal e Nascimento e da Organização Mundial de Saúde. Ciênc Saúde Coletiva. 2014; 19(7):1999- 
2010. doi: http://dx.doi.org/10.1590/141381232014197.08622013

2. Pereira SB, Diaz CMG, Backes MTS, Ferreira CLL, Backes DS. Good practices of labor and birth care from the perspective oh health profissionals. Rev Bras Enferm. 2018; 71(Suppl 3):1313-9. doi: dx.doi.org/10.1590/0034-7167-2016-0661

3. Monteiro MCM, Holanda, VR, Melo, GP. Analysis of humanized delivery concept according to the evolutionary method of rodgers. Rev Enferm Cent Oeste Min. 2017; 7:1-10. doi: http://dx.doi. org/10.19175/recom.v7i0.1885

4. Medeiros RMK, Teixeira RC, Nicolini AB, Alvares AS, Corrêa ACP, Martins DP. Humanized care: insertion of obstetric nurses in a teaching hospital. Rev Bras Enferm. 2016; 69(6):1029-36. doi: http://dx.doi. org/10.1590/0034-7167-2016-0295

5. Motta SAMF, Feitosa DS, Bezerra STF, Dodt RCM, Moura DJM. Implementation of humanized care to natural childbirth. Rev Enferm UFPE on line [Internet]. 2016 [cited Jun 13, 2019]; 10(2):593-9. Available from: https://pdfs.c92e0fe41f77c85de7250c4b0e71609603.pdf

6. Monteschio LVC, Sgobero JCGS, Oliveira RR, Serafim D, Mathias TAF. Prevalence of medicalization of labor and delivery in the public health network. Cienc Cuid Saude. 2016; 15(4):591-8. doi: dx.doi.org/10.4025/cienccuidsaude.v15i4.33420

7. Mselle LT, Kohi TW, Dol J. Barriers and facilitators to humanizing birth care in Tanzania: findings from semi-structured interviews with midwives and obstetricians. Reprod Health. 2018; 15(1):137. https://doi.org/10.1186/s12978-018-0583-7

8. Bardin L. Análise de conteúdo. São Paulo: Edições 70; 2016.

9. World health Organization. WHO recommendations Intrapartum care for a positive childbirth experience. Geneva: World health Organization; 2018.

10. Possati AB, Prates LA, Cremonese L, Scarton J, Alves CN. Humanization of childbirth: meanings and perceptions of nurses. Esc Anna Nery. 2017; 21(4): e20160366. doi: http://dx.doi.org/10.1590/2177-9465-ean-2016-0366

11. Moore ER, Bergman N, Anderson GC, Medley N. Early skin-to-skin contact for mothers and their healthy newborn infants. Cochrane Database Syst Rev. 2016; 11(25):CD003519. doi: https://doi. org/10.1002/14651858.CD003519.pub4
12. Ministério da Saúde (BR). Diretrizes nacionais de assistência ao parto normal: recomendações. Brasília: Ministério da Saúde; 2017.

13. Bourguignon AM, Grisotti M. Concepções sobre humanização do parto e nascimento nas teses e dissertações brasileiras. Saúde Soc. 2018, 27(4):1230-45. doi: https://doi.org/10.1590/ s0104-12902018170489

14. Braga TL, Santos SCC. Parto humanizado sob a ótica da equipe de enfermagem do Hospital da Mulher Mãe Luzia. Rev Eletr Estácio Saúde [Internet]. 2017 [citado 2019 jun 13]; 6(1):2033. Disponível: http://revistaadmmade.estacio. $\mathrm{br} /$ index.php/saudesantacatarina/article/ viewFile/3641/1563

15. Pereira SS, Oliveira ICMS, Santos JBS, Carvalho MCMP. Parto natural: a atuação do enfermeiro diante da assistência humanizada. Tempus Actas Saúde Coletiva. 2016; 10(3):199-213. doi: http:// dx.doi.org/10.18569/tempus.v10i3.1727

16. Biondi HS, Pinho EC, Kirchhof ALC, Rocha LP, Barlem ELD, Kerber NPC. Psychic workload in the process of work of maternity and obstetric centers nurses. Rev Gaúcha Enferm. 2018; 39:e 64573. doi: https://doi.org/10.1590/19831447.2018.64573

17. Fossa AM, Lino CM, Castilho, RAM, Rocha MCP, Horibe TM. A experiência da enfermeira durante a assistência à gestante no parto humanizado. Saúde Rev. 2015; 15(40):25-36. doi: https://doi. org/10.15600/2238-1244/sr.v15n40p25-36

18. Ferreira Júnior AR, Makuch MY, Osis MJMD, Barros NF. Percepções de profissionais de enfermagem sobre a humanização em obstetrícia. Sanare [Internet]. 2015 [citado 2019 jun 13]; 14(2):2735. Disponível em: https://sanare.emnuvens.com. br/sanare/article/view/821/492

19. Silva RC, Soares MC, Jardim VMR, Kerber NPC, Meincke SMK. The speech and practice of humanizing child birth in adolescente. Texto Context Enferm. 2013; 22(3):629-36. doi: https:// doi.org/10.1590/S0104-07072013000300008.

20. Rubashkin N, Minckas N. How should trainees respond in Situations of obstetric violence? Ama J Ethics. 2018; 20(1):238-46. doi: doi.org/10.1001/ journalofethics.2018.20.3.ecas2-1803 